\title{
Parasitic contamination of vegetables marketed in Arba Minch town, southern Ethiopia
}

\author{
Getaneh Alemu1*, Mohammedaman Mama², Direslgne Misker ${ }^{3}$ and Desta Haftu ${ }^{3}$
}

\begin{abstract}
Background: Consumption of unwashed, raw or unhygienically prepared fruits and vegetables act as potential source for the spread of various parasitic diseases. Moreover, the level of contamination and species of contaminant parasites vary from place to place because of variations in environmental and human factors. Therefore local determination of the level of contamination and associated factors is important for efficient intervention of infections acquired via those food items.

Methods: A Cross-sectional study was conducted among purchased vegetables in selected markets of Arba Minch town from January to March, 2018. A structured questionnaire was used to capture data about factors associated with parasitic contamination of vegetables in the marketing phase. Selected vegetables were purchased and processed for examination of parasitic contamination using direct wet mount, iodine wet mount and modified zeihl Neelson staining following standard protocols. All data were analyzed using SPSS version 20.0.

Results: Among 347 vegetable samples examined, 87(25.1\%) were contaminated with at least one parasite species. Tomato (35.0\%) was the most commonly contaminated vegetable while green pepper (10.6\%) was the least contaminated one. Entameoba histolytica/dispar (29, 8.4\%) was the commonest parasitic contaminant detected followed by Giardia lamblia $(24,6.9 \%)$ and oocyst of Cryptosporidium species (5.8\%). Vegetable type $\left(X^{2}=13.5 ; p=0\right.$. 009) and source of vegetables $\left(X^{2}=24.1 ; p<0.001\right)$ were significantly associated with parasitic contamination of vegetables.

Conclusion: Parasitic contamination rate among marketed vegetables in the present study is significantly considerable. Entameoba histolytica/dispar was the most frequently detected parasite. We recommend to the local public health sector to establish a system for continuous monitoring of contamination of vegetables sold at local markets.
\end{abstract}

Keywords: Vegetables, Contamination, Parasite, Market

\section{Background}

Consumption of fruits and vegetables is highly beneficial since they form the major component of a balanced diet [1]. Fruits and vegetables are important sources of carbohydrate, vitamins, minerals and fiber [2-4]. Considering such nutritional value, it is recommended that individuals should take a minimum of $400 \mathrm{~g}$ of fruits and vegetables per day. Fruits and vegetables also protect

\footnotetext{
*Correspondence: getanehmlt@gmail.com

${ }^{1}$ Department of Medical laboratory Science, Bahir Dar University, Bahir Dar, Ethiopia

Full list of author information is available at the end of the article
}

people from different non-infectious chronic diseases like cardiovascular problems $[4,5]$. However; consumption of unwashed, raw or unhygienically prepared fruits and vegetables act as potential sources for the spread of various infectious diseases $[2,3,6,7]$.

Vegetables can be contaminated while growing in fields due to use of organic fertilizer or contaminated irrigation water or during harvesting, processing, distribution, sale and during consumption [8]. As a result, they have been involved in food-borne outbreaks [9]. Infective stages of intestinal parasites (IPs) are the most common contaminants of vegetables, as they are abundant in the environment [10]. 
Parasites such as Cryptosporidium species (spp), Giardia lamblia (G.lamblia), Entamoeba histolytica (E.histolytica), Ascaris lumbricoides (A.lumbricoides), hookworms, Enterobius vermicularis (E.vermicularis), Trichuris trichiura (T.trichiura), Toxocara spp., Hymenolepis spp., Taenia spp., Fasciola spp. and members of the family Trichostrongylidae could infect humans [11]. Hence, globally, an estimated 3.5 billion people are infected, and 450 million are sick from intestinal parasite infections (IPIs), with an estimated 200,000 deaths each year [12]. Intestinal parasites cause significant morbidity and mortality throughout the world, especially in tropical and sub-tropical countries [13]. Infection with IPs has been known to cause iron deficiency anemia, growth retardation in children and other physical and mental health problems $[14,15]$.

An effective way of selecting appropriate intervention steps to reduce pathogenic micro-organisms on vegetables is to identify sources of contamination and ecology of the pathogens [16]. However, in developing countries including Ethiopia, the medical impact of food-borne diseases is not known or under estimated because of absence of routine diagnosis and monitoring for the etiologic agents of food-borne infections [17]. The risk has been reported to be higher in towns, where there is poor hygienic and sanitary practice accompanied with overcrowding $[5,13]$.

Vegetables may get exposed to parasite contaminants in the pre-harvest (cultivation, irrigation, livestock manure) and post-harvest handling (storage, transportation) phases or while processing for consumption [18, 19]. Use of insufficiently treated wastewater and improperly composted manures are responsible for the high rates of parasitic contamination [18, 20]. Bad hygienic practice during production, transport, processing and preparation by handlers including consumers also contribute in vegetable contaminations [21].

Gamo Gofa Zone is known for the production of diverse types of fruits and vegetables that some cover the majority of country level consumption and others are distributed by retailers for local consumption. In Arba Minch (capital of the zone), it is common to see fruits and vegetables being sold in shops, at open markets and more commonly at road sides. It is also common to observe people buying those fruits and vegetables and eating in raw without washing. Despite this, the local health care units have no system to monitor the risks posed by unhygienic marketing and consumption of fruits and vegetables. A study conducted in Arba Minch town in 2014 showed a parasitic contamination rate of $54.4 \%$ [22]. Since then, efforts have been made to improve the water supply; sanitation and hygiene (WASH) of the population. Moreover national bi-annual deworming of risk population groups is being implemented since November 2015. Even though we suggest all these efforts indirectly decrease the contamination rate of vegetables, it should be supported by research based evidence. Therefore, this study was designed to determine the level of parasitic contamination of selected vegetables and associated factors in local markets of Arba Minch Town, Ethiopia.

\section{Methods}

\section{Study design and area}

A cross-sectional study was conducted from January to March 2018 among markets located in Arba Minch Town. Arba Minch is the capital of Gamo Gofa zone found in the Southern Nations Nationalities and Peoples Region, Southern Ethiopia. It is located at low altitude (1200-1300 $\mathrm{m}$ above sea level). The hot climate (annual temperature of $29.7^{\circ} \mathrm{C}$ ) makes the area to be conducive for cultivation of fruits and vegetables like Banana, Mango, cabbage, salad, carrot and many others [23].

\section{Sample collection}

A pre-tested structured questionnaire was used to collect data about pre-disposing factors for parasitic contamination of vegetables at local markets. The questionnaire was prepared in English and translated to Amharic. The Amharic version was administered to vegetable vendors by face to face interview. About $0.2 \mathrm{kgs}$ of vegetables were purchased at four local markets (Sikela, shecha, Yetnebersh and Konso sefer). A total of 100 Lycopersicon esculentum (tomato), 96 Brassica oleracea (cabbage), 66 Capsicum annuum (Green pepper), 62 Daucus carota (carrot) and 23 Lactuca sativa (salad), totally 347, samples were purchased and transported through transporting cold box to the Medical Parasitology Teaching Laboratory of Bahir Dar University. All the samples were processed and examined for parasitological contamination within 24 $\mathrm{h}$ of collection.

\section{Sample processing}

A $100 \mathrm{~g}$ of each vegetable was chopped and immersed in $500 \mathrm{ml}$ of physiological saline in graduated beaker. The contents were thoroughly agitated using a shaker in order to facilitate adequate washing.

The washing solution was then allowed to stand on the bench for overnight to allow time for proper sedimentation. Then a sediment for microscopic examination was prepared following a procedure explained elsewhere [24]. About $100 \mu \mathrm{l}$ sediment was transferred to a clean glass slide, covered with cover slide and examined under light microscope using $\times 10$ and $\times 40$ objectives. Two slide preparations were examined for each sediment just to increase the sensitivity of the test. Another preparation of the sediment was examined by adding a drop of Lugol's iodine before adding cover slide in order to easily detect parasite ova/cysts. Modified Zeihl-Neelsen staining 
technique was used for identification of oocysts of Cryptosporidium, Isospora and Cyclospora species as described elsewhere [25].

\section{Statistical analysis}

Data collected from questionnaire and results of laboratory investigations were cleaned, entered and analysed using SPSS version 20.0. The percentage of vegetables contaminated with different types of medically important parasites were calculated. Chi-square test and logistic regression analysis were used to identify factors associated with parasitic contamination. Association between variables was considered statistically significant only if $P$-value $\leq 0.05$ at $95 \%$ confidence level. The strength of association was measured through adjusted odds ratios (AOR).

\section{Results}

A total of 347 vegetable samples were collected from local markets and examined for parasitological contamination. Vegetables were collected from four local markets namely Sikela (66.3\%), Shecha (16.4\%), Konso sefer (10.4\%) and Yetnebersh (6.9\%). Results of parasitological investigation showed that 87 vegetable samples were microscopically positive for at least one parasite. This gives an overall contamination rate of $25.1 \%$ (95\%CI, 21.0-29.7). Among a total of 87 contaminated samples, $61(70.1 \%)$ and 26 (29.9\%) were contaminated with one and two parasite species respectively (Table 1 ).

The species and stages of parasites detected were ova of A. lumbricoides and hookworms; cysts of G. lamblia, E. histolytica/dispar and Balantidium coli (B. coli); oocysts of Cryptosporidium and Cyclospora species; and larvae of Strongyloides like parasite. Cyst of E. histolytica/dispar (8.4\%) was the most frequently detected parasite followed by cyst of G. lamblia (6.9\%) and oocyst of Cryptosporidium species (5.8\%). Among the five vegetable types included in the study, E. histolytica/dispar was detected only in two vegetables namely tomato (22/ 29 ) and carrot (7/29). On the contrary, G. lamblia was abundantly detected in samples of cabbage (16/24) followed by green pepper and carrot (4/24 in each) (Table 2).

\section{Factors associated with parasitic contamination of vegetables}

As analyzed using the chi-square $\left(\mathrm{X}^{2}\right)$ test, kind of vegetables were significantly associated with parasitic contamination $(p=0.009)$. Tomato $(35 \%)$ was the most frequently contaminated vegetable followed by carrot (29\%), cabbage (24\%), salad (17.4\%) and green pepper (10.6\%) (Table 3). Binary logistic regression analysis also showed that, as compared to green pepper, tomato was significantly less contaminated (AOR: 0.436; 95\% confidence interval (CI): 0.192-0.991). Among 347 interviewed vendors, 290 have attended primary school while 36 and 21 have no formal education and secondary/ above respectively. However, educational status of vendors was not significantly associated with parasitic contamination of vegetables $(p=0.086)$. The majority of vendors $(74.9 \%)$ responded that they purchase vegetables directly from farmers while the rest $(25.1 \%)$ are supplied by large scale vendors. These sources of vegetables were significantly associated with parasitic contamination level $(p<0.001)$ indicating that vegetables directly supplied by farmers were 3.547 times at higher risk of contamination as compared to those distributed by large scale vendors (AOR: 3.547; 95\%CI: 2.066, 6.109) (Table 4).

\section{Discussion}

In recent years, the federal ministry of health, in collaboration with concerned non-governmental organizations, is showing strong commitment to combat the public health impact of human parasites. However, the burden of intestinal parasitosis is still unacceptably high due to favorable climatic conditions, unsanitary conditions and little awareness by the community about the transmission and prevention of parasitic diseases. Open defecation is common in Ethiopia which, in

Table 1 Frequency distribution of parasitic contamination among vegetables sold in local markets of Arba Minch Town from January to March 2018

\begin{tabular}{lllll}
\hline $\begin{array}{llll}\text { Vegetable } \\
\text { Type }\end{array}$ & $\begin{array}{l}\text { Number } \\
\text { Examined }\end{array}$ & $\begin{array}{l}\text { Number } \\
\text { positive }(\%)\end{array}$ & \multicolumn{2}{l}{ Number of parasitic species detected (\%) } \\
\cline { 5 - 5 } Tomato & 100 & $35(35.0)$ & $22(22)$ & One \\
Cabbage & 96 & $23(24.0)$ & $19(19.8)$ & $4(4.2)$ \\
Green pepper & 66 & $7(10.6)$ & $6(9.1)$ & $1(1.5)$ \\
Carrot & 62 & $18(29.0)$ & $12(19.4)$ & $6(9.6)$ \\
Salad & 23 & $4(17.4)$ & $2(8.7)$ & $2(8.7)$ \\
Total (\%) & 347 & $87(25.1)$ & $61(17.6)$ & $26(7.5)$ \\
\hline
\end{tabular}


Table 2 Prevalence of parasites among vegetables sold in local markets of Arba Minch Town from January to March 2018

\begin{tabular}{|c|c|c|c|c|c|c|c|c|c|c|}
\hline \multirow{2}{*}{$\begin{array}{l}\text { Vegetable } \\
\text { Type }\end{array}$} & \multirow{2}{*}{$\begin{array}{l}\text { Number } \\
\text { Examined }\end{array}$} & \multicolumn{8}{|c|}{ Number Contaminated with } & \multirow{2}{*}{$\begin{array}{l}\text { Total } \\
\text { contaminatec } \\
\text { (\%) }\end{array}$} \\
\hline & & E.histolytica & G.lamblia & $\begin{array}{l}\text { Cryptosporidium } \\
\text { spp }\end{array}$ & $\begin{array}{l}\text { B. coli like } \\
\text { spp }\end{array}$ & A.lumbricoides & $\begin{array}{l}\text { Cyclospora } \\
\text { spp }\end{array}$ & Hookworms & $\begin{array}{l}\text { Strongyloides } \\
\text { like }\end{array}$ & \\
\hline Tomato & 100 & 22 & 0 & 9 & 0 & 6 & 4 & 3 & 4 & $35(35.0)$ \\
\hline Cabbage & 96 & 0 & 16 & 0 & 4 & 0 & 0 & 4 & 3 & $23(24.0)$ \\
\hline G.pepper $^{*}$ & 66 & 0 & 4 & 2 & 6 & 0 & 2 & 0 & 0 & $7(10.6)$ \\
\hline Carrot & 62 & 7 & 4 & 7 & 4 & 3 & 0 & 0 & 0 & 18(29.0) \\
\hline Salad & 23 & 0 & 0 & 2 & 1 & 0 & 1 & 0 & 0 & $4(17.4)$ \\
\hline Total (\%) & 347 & $29(8.4)$ & $24(6.9)$ & $20(5.8)$ & $15(4.3)$ & $9(2.6)$ & $7(2)$ & $7(2)$ & $7(2)$ & $87(25.1)$ \\
\hline
\end{tabular}

*G.pepper = green pepper

turn, contaminates raw edible fruits and vegetables as well as water [26].

The overall parasitic contamination rate in the present study was $25.1 \%$ which is in line with findings from Nigeria and Iran [10, 27]. However it is lower than many of the previous findings elsewhere [22, 28-34]. On the other hand, it is higher as compared to studies from Iran, Turkey, Maiduguri (Nigeria) and Sudan [34-36]. These variations between the present study and previous results might be due to variations in geographical locations, climatic and environmental conditions, the kind of fruit and vegetable samples examined and number of fruits/vegetables examined, laboratory methods used, and sanitary status of the community.
As compared to similar study conducted in Arba Minch town in 2014, the present study showed a decrease in contamination rate by more than half $(54.4 \%$ vs $25.1 \%$ ) [22]. These differences might be due to ongoing bi-annual deworming program targeting helminthiasis. Moreover, improvements in the implementation of WASH program accompanied with continuous health education by the health extension workers to avoid open defecation might also play an important role. Differences in kind and number of fruits and vegetables assessed could also be responsible for the discrepancy.

In this study, tomato (35.0\%) was the most frequently contaminated vegetable. On the contrary, tomato was the least contaminated vegetable according to previous

Table 3 chi-square test of factors associated with parasitic contamination of vegetables sold in local markets of Arba Minch Town from January to March 2018

\begin{tabular}{|c|c|c|c|c|c|}
\hline Variables & Category & Number examined & Rate of parasite contam inated N (\%) & $x^{2}$ & P-value \\
\hline \multirow[t]{5}{*}{ Vegetable type } & Tomato & 100 & $35(35.0)$ & & \\
\hline & Salad & 23 & $4(17.4)$ & & \\
\hline & Cabbage & 96 & $23(24.0)$ & 13.484 & 0.009 \\
\hline & Carrot & 62 & 18(29.0) & & \\
\hline & Green pepper & 66 & $7(10.6)$ & & \\
\hline \multirow[t]{2}{*}{ Washed before display } & Yes & 49 & 19(38.8) & 5.703 & 0.117 \\
\hline & No & 298 & $68(22.8)$ & & \\
\hline \multirow[t]{4}{*}{ Market } & Sikela & 230 & $48(20.9)$ & & \\
\hline & Yetnebersh & 24 & $12(50.0)$ & 1.465 & 0.210 \\
\hline & Shecha & 57 & 15(26.3) & & \\
\hline & Konso sefer & 36 & 12(33.3) & & \\
\hline \multirow[t]{2}{*}{ Means of display } & On the floor & 338 & $84(24.9)$ & 0.336 & 0.562 \\
\hline & On table/shelf & 9 & 6 & & \\
\hline \multirow[t]{3}{*}{ Handled by vendor who has } & No formal edu & 36 & $6(16.7)$ & & \\
\hline & Primary school & 290 & $72(24.8)$ & 4.899 & 0.086 \\
\hline & Secondary/above & 21 & $9(42.8)$ & & \\
\hline \multirow[t]{2}{*}{ Source of vegetables } & Farmers & 260 & $48(18.5)$ & 24.122 & 0.000 \\
\hline & Large scale vendors & 87 & $39(44.8)$ & & \\
\hline
\end{tabular}


Table 4 Binary logistic regression of factors associated with parasitic contamination of vegetables sold in local markets of Arba Minch Town from January to March 2018

\begin{tabular}{|c|c|c|c|c|c|c|c|}
\hline Variables & Category & $\begin{array}{l}\text { Number } \\
\text { examined }\end{array}$ & $\begin{array}{l}\text { Rate of parasite contam } \\
\mathrm{N}(\%)\end{array}$ & $\begin{array}{l}\text { Crude Odds Ratio } \\
(95 \% \mathrm{Cl})\end{array}$ & $\begin{array}{l}P \text { - } \\
\text { value }\end{array}$ & AOR $(95 \% \mathrm{Cl})$ & $\begin{array}{l}P- \\
\text { value }\end{array}$ \\
\hline \multirow[t]{5}{*}{ Vegetable type } & Tomato & 100 & $35(35.0)$ & $0.22(0.091,0.534)$ & 0.01 & $0.321(0.109,0.939)$ & 0.038 \\
\hline & Salad & 23 & $4(17.4)$ & $0.564(0.149,2.137)$ & 0.399 & $1.200(0.320,4.504)$ & 0.787 \\
\hline & Cabbage & 96 & $23(24.0)$ & $0.377(0.151,0.938)$ & 0.036 & $0.533(0.177,1.608)$ & 0.264 \\
\hline & Carrot & 62 & 18(29.0) & $0.290(0.111,0.755)$ & 0.011 & $0.352(0.113,1.101)$ & 0.073 \\
\hline & Green pepper & 66 & $7(10.6)$ & 1 & & & \\
\hline \multirow[t]{2}{*}{ Washed before display } & Yes & 49 & 19(38.8) & 1 & & & \\
\hline & No & 298 & $68(22.8)$ & $2.142(1.135,4.043)$ & 0.019 & $0.534(0.191,1.493)$ & 0.232 \\
\hline \multirow[t]{4}{*}{ Market } & Sikela & 230 & $48(20.9)$ & $1.896(0.884,4.064)$ & 0.100 & $2.117(0.783,5.727)$ & 0.139 \\
\hline & Yetnebersh & 24 & 12(50.0) & $0.500(0.173,1.441)$ & 0.199 & $0.972(0.278,3.398)$ & 0.965 \\
\hline & Shecha & 57 & 15(26.3) & $1.400(0.564,3.477)$ & 0.469 & $0.953(0.302,3.001)$ & 0.934 \\
\hline & Konso sefer & 36 & 12(33.3) & 1 & & & \\
\hline \multirow[t]{2}{*}{ Means of display } & On the floor & 338 & $84(24.9)$ & $1.512(0.370,6.178)$ & 0.565 & & \\
\hline & On table/shelf & 9 & 6 & 1 & & & \\
\hline \multirow[t]{3}{*}{ Handled by vendor who has } & No formal edu & 36 & $6(16.7)$ & $3.750(1.095,12.842)$ & 0.035 & $2.864(0.645,12.716)$ & 0.166 \\
\hline & Primary school & 290 & $72(24.8)$ & $2.271(0.919,5.610)$ & 0.076 & $1.088(0.318,3.726)$ & 0.893 \\
\hline & Secondary/above & 21 & $9(42.8)$ & 1 & & & \\
\hline \multirow[t]{2}{*}{ Source of vegetables } & Farmers & 260 & $48(18.5)$ & $3.589(2.121,6.072)$ & 0.000 & $3.547(2.066,6.109)$ & 0.000 \\
\hline & Large scale vendors & 87 & $39(44.8)$ & 1 & & & \\
\hline
\end{tabular}

studies [30, 32]. Leafy vegetables and/or those with uneven surfaces (salad, cabbage) make the parasitic stages more easily attach to their surfaces unlike to those having smooth surface (green pepper, tomato) [37]. Our finding is against the logic because we didn't include equal number of the vegetables from each kind and very few numbers of samples were examined especially for salad. However, compared to green pepper, tomato was $32.1 \%$ less likely to be contaminated with parasites, similarly with study findings in Nigeria [10].

In the present study, cyst of E. histolytica/dispar (8.4\%) was the most frequently detected parasite followed by $G$. lamblia (6.9\%) which is in line with previous finding from Sudan [33]. However it varies among many other studies $[10,30-33,35]$. Iodine wet mount was examined in the present study which increases the sensitivity of stool microscopy for detection of protozoa cysts. Ova of A.lumbricoides were the predominant contaminants according to previous similar study done in Arba Minch. The national deworming program against soil transmitted helminths might bring this shift. In addition to this, variation in the season and kind of fruits and vegetables considered also matters.

Cryptosporidium spp (5.8\%) was the third most common parasitic contaminant in the present study. However, the rate of contamination was lower as compared to findings from Ghana (17\%), Egypt (29.3\%) and Jimma, Ethiopia $(12.8 \%)[4,7,30]$. It is common to use animal excreta as fertilizer in the study area that we had expected higher rate of Cryptosporidium contamination. However, variations in the laboratory methods used might bring this variation as we used only ziehl Neelson staining technique.

Double contamination by two parasite species was observed in all kinds of vegetables (7.5\%) but the rate of double infection is much lower as compared to studies conducted in different parts of Ethiopia. In addition, unlike to the previous studies, no more than two parasites have contaminated the same vegetable sample at a time $[22,26]$. This is an indication that the level of contamination of vegetables is decreasing owing to implementation of parasite control activities in the country.

Vegetables directly supplied by farmers to vendors were 3.5 times more likely to be contaminated with parasites as compared to vegetables supplied by large scale vendors. Large scale vendors receive vegetables on the farm land, pack and transport to Arba Minch town using their vehicle, store it properly and distribute to small scale vendors. On the other hand, small scale vendors who receive vegetables directly from farmers transport it either via back of animals or human labor; vegetables are readily exposed to contamination in this case.

In the present study, display of vegetables without washing was not significantly associated with parasitic contamination $(p=0.232)$ with probable reason of few number of washed vegetables included in the study $(n=$ 
49). However, previous studies in Turkey and Iran showed that washing of vegetables contributes for significant decrease in the rate of parasitic contamination $[37,38]$. According to study results by Fallah et al, traditional washing with tap water reduces rate of parasitic contamination (32.6\% vs $1.3 \%$ ) but does not totally remove parasites from vegetables. Pre-washing could not inactivate viable infectious parasitic stages. Hence, in order to totally remove parasites, vegetables need to be washed following standard technique using chemicals like calcium hypochlorite and automated fruit-vegetable washer [38].

Previous studies have identified that means of display, type of water used for washing before display and contamination extent of irrigation water were significantly associated with parasitic contamination of vegetables $[10,30,34]$. In order to identify potential sources or factors which contribute for parasitic contamination of vegetables, large scale follow up study starting from farm to in-house consumption is recommended.

\section{Conclusion}

The present study reveals that parasitic contamination rate in vegetables sold at Arba Minch local markets is significantly considerable. E. histolytica/dispar was the most frequently detected parasite. Vegetable types were determinant factors for variations in rate of contamination that tomato was the most commonly contaminated vegetable. Vegetables directly supplied by farmers to vendors were more prone for contamination as compared to those supplied by large scale vendors. We recommend to the local public health sector to establish a system for continuous monitoring of contamination of vegetables sold at local markets. The public health sector should also advocate to the community not to consume vegetables without adequate washing or proper cooking. Finally we call up further study considering seasonal variations in order to exhaustively assess associated factors.

\section{Abbreviations}

AOR: Adjusted odds ratio; Cl: Confidence interval; IPIs: Intestinal parasitic infections; IPs: Intestinal parasites; WASH: Water sanitation and hygiene

\section{Acknowledgments}

The authors thank Arba Minch University for giving ethical clearance. The authors' gratitude goes to Mr. Sefraye Batre for his kind participation during sample collection and laboratory analysis. The authors' regards also go to the vegetable vendors of Arba Minch town who participated in the study.

\section{Funding}

Fund for data collection was obtained from Arba Minch University. No fund was obtained for designing of the study, result interpretation and manuscript writing.

\section{Authors' contributions}

GA conceived and designed the project. GA and MM performed the experiment. GA, MM, DM and DH analyzed the data and wrote the manuscript. All authors have read and approved the manuscript.

\section{Ethics approval and consent to participate}

Ethical approval for the research was granted by review board of Arba Minch University, College of Medicine and Health Science with a project code of Gov/AMU/TH.4.2./CMHS/MLS/04/09. Official permission letter was obtained from Arba Minch town. According to Arba Minch University ethics protocol, verbal consent is enough in order to collect questionnaire data and biological samples collected by non-invasive procedures. Hence, verbal consent was obtained from each vendor.

\section{Consent for publication}

Not applicable.

\section{Competing interests}

The authors declare that they have no competing interests.

\section{Publisher's Note}

Springer Nature remains neutral with regard to jurisdictional claims in published maps and institutional affiliations.

\section{Author details}

'Department of Medical laboratory Science, Bahir Dar University, Bahir Dar, Ethiopia. ${ }^{2}$ Department of Medical laboratory Science, Madda Walabu University Goba Referral Hospital, Robe, Ethiopia. ${ }^{3}$ Department of public health, Arba Minch University, Arba Minch, Ethiopia.

Received: 24 September 2018 Accepted: 25 April 2019

Published online: 14 May 2019

\section{References}

1. Okyay P, Ertug S, Gultekin B, Onen O, Beser E. Intestinal parasites prevalence and related factors in school children, a western city sample-Turkey. BMC Public Health. 2004:4(64). https://doi.org/10.1186/1471-2458-4-64

2. Nazemi S, Raei M, Amiri M, Chaman R. Parasitic contamination of raw vegetables in Shahroud, Semnan. Zahedan. J Res Med Sci. 2012;14(8):84-6.

3. Ebrahimzadeh A, Jamshidi A, Mohammadi S. The parasitic contamination of raw vegetables consumed in Zahedan, Iran. Health Scope. 2013;1(4):205-9.

4. Duedu K, Yarnie E, Tetteh-Quarcoo P, Attah S, Donkor E, Ayeh-Kumi PA. Comparative survey of the prevalence of human parasites found in fresh vegetables sold in supermarkets and open-aired markets in Accra,Ghana. BMC Res Notes. 2014;7:836.

5. Wegayehu T, Tsalla T, Seifu B, Teklu T. Prevalence of intestinal parasitic infections among highland and lowland dwellers in Gamo area, South Ethiopia. BMC Public Health. 2013;13:151.

6. Izadi SH, Abedi S, Ahmadian S, Mahmoodi M. Study of the current parasitic contamination of the edible vegetables in Isfahan in order to identify preventive measures. Sci J Kurdistan Univ Med Sci. 2006;11:51-8.

7. Said D. Detection of parasites in commonly consumed raw vegetables. Alexandria J Med. 2012;48:345-52.

8. Beuchat LR. Pathogenic Microorganisams associated with fresh produce. J Food Prot. 1995;59(2):204-16

9. WHO. Food borne Diseases, Emerging, <<http://www.who.int/mediacentre/ factsheets/fs124/en/print.html >>. 2002.

10. Luka J, Biu AA, Babayo AM, Kyari F, Mohammed YM, Sonibare AO. Prevalence of helminths on raw vegetables and hygienic practices among vegetable marketers in Maiduguri, Borno state, Nigeria. Niger J Parasitol. 2016;37(2):169-73

11. Kozan E, Gonenc B, Sarimehmetoglu O, Aycicek H. Prevalence of helminth eggs on raw vegetables used for salads. Food Control. 2005;16:239-42.

12. Wakid HM. Improvement of Ritchie technique by identifying the food that can be consumed pre-analysis. J App Sci. 2009;5:293-6.

13. Nyarango RM, Aloo PA, Kabiru EW, Nyanchongi BO. The risk of pathogenic intestinal parasite infections in Kisii municipality, Kenya. BMC Public Health. 2008;8:237.

14. Evans AC, Stephenson LS. Not by drugs alone: the fight against parasitic helminths. World Health Forum. 1995;16:258-61. 
15. WHO. De-worming for health and development. In: Report of the third global meeting of the partners for parasite control, Geneva; 2005.

16. Malann YD, Tim UI. The prevalence of intestinal parasites on fruits sold in markets around Gwagwalada area council, F.C.T, Abuja. AASCIT communications. 2016;3(2):107-11.

17. Dorny P, Praet N, Deckers N, Gabriel S. Emerging food-borne parasites. Vet Parasitol. 2009;163(3):196-206.

18. Mahvi AH, Kia EB. Helminth eggs in raw and treated wastewater in the Islamic Republic of Iran. East Mediterr Health J. 2006;12(1-2):137-43.

19. Erkan EM, Vural A. Investigation of microbial quality of some leafy green vegetables. J Food Tech. 2008;6:285-8.

20. Beuchat LR. Ecological factors influencing survival and growth of human pathogens on raw fruits and vegetables. Microbes Infect. 2002;4(4):413-23.

21. Gupta S, Satpati S, Nayek S, Garai D. Effect of wastewater irrigation on vegetables in relation to bioaccumulation of heavy metals and biochemical changes. Environ Monit Assess. 2010;165(1-4):169-77.

22. Fitsum B, Tamirat T, Gelila B, Tsegaye Y. Parasitic contamination of raw vegetables and fruits collected from selected local markets in Arba Minch town, Southern Ethiopia. Infect Dis Poverty. 2017;6:19. https://doi.org/10. 1186/s40249-016-0226-6

23. Ayalew A. Knowledge and practice of malaria prevention methods among residents of Arba Minch town and Arba Minch Zuria District, Southern Ethiopia. Ethiop J Health Sci. 2010;20(3):185-93.

24. Idahosa OT. Parasitic contamination of fresh vegetables sold in Jos markets. Glob J Med Res. 2011;11(1):20-5.

25. Cheesbrough M. District Laboratory Practice in Tropical Countries, pp. 206207, part 1. New York, USA: Cambridge University Press; 2009.

26. Omowaye OS, Audu PA. Parasites contamination and distribution on fruits and vegetables in Kogi, Nigeria. Cibtech J Bio-Protocols. 2012;1 (1):44-7.

27. Fallah AA, Makhtumi Y, Pirali-Kheirabadi K. Seasonal study of parasitic contamination in fresh salad vegetables marketed in Shahrekord, Iran. Food Control. 2016;60:538-42.

28. Abougrain AK, Nahaisi MH, Madi NS, Saied MM, Ghenghesh KS. Parasitological contamination in salad vegetables in Tripoli-Libya. Food Control. 2010;21(5):760-2.

29. WHO. Surface decontamination of fruits and vegetable eaten raw. In: Food safety programme document; 2009. p. 4-30.

30. Tefera T, Biruksew A, Mekonnen Z, Eshetu T. Parasitic Contamination of Fruits and Vegetables Collected from Selected Local Markets of Jimma Town, Southwest Ethiopia. Int Scholarly Res Notices. 2014;2014:7.

31. Hajjami K, Ennaji MM, Amdiouni H, Fouad S, Cohen N. Parasistic contamination on fresh vegetable consumed in Casablanca City (Morocco) and risk for consumer. Int J Sci Technol. 2013;2(7):543-9.

32. Duedu KO, Yarnie EA, Tetteh-Quarcoo PB, Attah SK, Donkor ES, Ayeh-Kumi PF. A comparative survey of the prevalence of human parasites found in fresh vegetables sold in supermarkets and open-aired markets in Accra, Ghana. BMC Research Notes. 2014;7:836-41.

33. Alli JA, Abolade GO, Kolade AF, Salako AO, Mgbakor CJ, Ogundele MT, Oyewo AJ, Agboola MO. Prevalence of intestinal parasites on fruits available in Ibadan markets, Oyo state, Nigeria. Acta Parasitol Globalis. 2011;2(1):6-10.

34. Mohamed MA, Siddig EE, Elaagip AH, Edris AMM, Nasr AA. Parasitic contamination of fresh vegetables sold at central markets in Khartoum state, Sudan. Ann Clin Microbiol Antimicrob. 2016;15:17-23.

35. Saki J, Asadopoori R, Vatan SK. Prevalence of intestinal parasites in vegetables consumed in Ahvaz, south west of Iran. J Med Sci. 2013; 13(6):488-92.

36. Adamu NB, Adamu JY, Mohammed D. Prevalence of helminth parasites found on vegetables sold in Maiduguri, Northeastern Nigeria. Food Control. 2012:25:23-6.

37. Avcioglu H, Soykan E, Tarakci U. Control of helminth contamination of raw vegetables by washing. Vector-Borne Zoonotic Dis. 2011;11(2):189-91.

38. Fallah AA, Pirali-Kheirabadi K, Shirvani F, Saei-Dehkordi SS. Prevalence of parasitic contamination in vegetables used for raw consumption in Shahrekord, Iran: influence of season and washing procedure. Food Control. 2012;25(2):617-20

\section{Ready to submit your research? Choose BMC and benefit from:}

- fast, convenient online submission

- thorough peer review by experienced researchers in your field

- rapid publication on acceptance

- support for research data, including large and complex data types

- gold Open Access which fosters wider collaboration and increased citations

- maximum visibility for your research: over $100 \mathrm{M}$ website views per year

At BMC, research is always in progress.

Learn more biomedcentral.com/submissions 